\title{
Action Mechanism and Model of Cross-Border E-Commerce Green Supply Chain Based on Customer Behavior
}

\author{
Xiaheng Zhang ${ }^{1,2}$ and Sukun Liu $\mathbb{1 D}^{3}$ \\ ${ }^{1}$ School of Economics and Management, Chuzhou University, Chuzhou 239000, Anhui, China \\ ${ }^{2}$ College of Business and Trade, Nanchang Institute of Science and Technology, Nanchang 330108, China \\ ${ }^{3}$ School of Economic and Management, Dalian Ocean University, Dalian 116001, Liaoning, China \\ Correspondence should be addressed to Sukun Liu; liusukun@dlou.edu.cn
}

Received 25 December 2020; Revised 12 May 2021; Accepted 25 June 2021; Published 8 July 2021

Academic Editor: Aijun Liu

Copyright (c) 2021 Xiaheng Zhang and Sukun Liu. This is an open access article distributed under the Creative Commons Attribution License, which permits unrestricted use, distribution, and reproduction in any medium, provided the original work is properly cited.

\begin{abstract}
In recent years, China's cross-border e-commerce has flourished, and the transaction volume has increased year by year. Crossborder e-commerce has become a favorable breakthrough point for China's foreign trade. This article mainly studies the action mechanism and model of cross-border e-commerce green supply chain based on customer behavior. Green supply chain partners select 24 secondary indicators of the evaluation system as the input vector. The historical data of each index is collected by field investigation as sample data and brought into the neural network for training. The output vector of the only output layer of the network is used as the evaluation result of the supplier. This paper divides the operation mode of green supply chain into four stages and puts forward improvement tools for the functional modules in each stage. Enterprises can use the tools in the modules to improve the operation efficiency of green supply chain. According to the green level evaluation demand of green supply chain, this paper uses the hierarchical method to evaluate it. According to the survey results, this paper uses arithmetic average method to deal with the operation and establishes a secondary index after decomposition. Finally, this paper uses confirmatory factor analysis to test the measurement model and further uses analysis of variance to test the relationship between the two types of social cues and behavioral willingness. The data shows that the orderly fluctuation range of the east, middle, and west cross-border logistics subsystems basically remains at around 0.2 to 0.6 . The results show that the establishment of the green supply chain model has a very positive significance for the implementation and development of the green supply chain in China's manufacturing industry. Through the research of profit and profit distribution in the green supply chain, it provides guidance for the green supply chain to effectively select the supply chain members to cooperate and calculate and distribute the profit reasonably, so that the green supply chain management can be widely used in reality.
\end{abstract}

\section{Introduction}

In recent years, China's economy has been under great downward pressure, and the cost of manufacturing industry is rising. The traditional foreign trade mode and large cross-border trade have been greatly impacted [1]. Compared with traditional foreign trade, at present, China's Internet economy is in the leading position in the world, and the cross-border e-commerce industry is developing rapidly. Online retailing, especially small crossborder transactions, shows great competitive advantages. Simultaneously, the national policies continue to be favorable to support the development of cross-border e-commerce [2].

It is a general trend that Chinese goods are sold to consumers all over the world through e-commerce and will gradually replace traditional trading methods. In this context, it has become more and more difficult to realize the development of enterprises only relying on cost-effective products $[3,4]$. Only by making breakthroughs on the product side, channel side, brand building, and supply chain building at the same time can they have a foothold in the fierce competition [5]. Through the research of this article, we provide selection criteria and basis for the platform's 
overseas warehouse construction model. This has important practical significance for the improvement and innovation of the existing cross-border logistics model, improvement of logistics links, and promotion of China's foreign trade structure adjustment and power conversion [6].

The development of the green supply chain has greatly enhanced the competitiveness of Chinese enterprises. The motivation of Kang's research is to activate recent poverty alleviation practices in the green supply chain. He examined the individual behaviors and cooperative behaviors of supply chain participants in the "green poverty alleviation" supply chain; that is, manufacturers initiate product "greening" and provide microcredit to alleviate the poverty of poor raw material suppliers. By establishing a series of supply chain game models, he analyzed the impact of cooperation mechanisms on green levels, prices, and profits and examined the impact of consumers' green sensitivity and small loan interest rates. On this basis, he proposed an optimal cooperation mechanism based on a two-part tariff contract. He also proposed to improve the economic and environmental performance of the supply chain "green poverty alleviation" through cooperation [7]. Rezaee proposed a two-stage stochastic planning model to design a green supply chain in a carbon trading environment. The model solves the discrete location problem and determines the optimal material flow and carbon credits/subsidies for transactions. He has contributed to the development of the supply chain by incorporating the uncertainty of carbon prices and product demand. He applied the model to actual case studies and carefully analyzed and explained the numerical results. Although his research has certain positive significance, it is not very innovative [8]. Wu believes that although people pay more and more attention to sustainable development and green innovation, in the context of supply chain relations, especially in emerging countries like China, few empirical efforts have been made to explore the factors affecting the performance of green innovation. In order to solve this research gap, he studied the role of specific investment in green supply chain innovation from the perspective of specific investment. He proposed that knowledge transfer plays a mediating role in the relationship. According to stakeholder participation theory, he believes that the social responsibility of partners plays a moderate role in not only specific investment (green supply chain innovation performance linkage) but also knowledge transfer and performance linkage. He tested the proposed relationship with a sample of 331 questionnaires and verified the responses from 187 high-tech companies in China. The external factors considered in his research are not comprehensive [9]. Pourjavad believes that the qualitative criteria for evaluating the performance of green supply chain management (GSCM) are affected by uncertainty, which is mainly due to the inherent ambiguity in the evaluation of qualitative factors. He aims to reduce the uncertainty caused by human judgment in the GSCM performance evaluation process using language terms and membership. He proposed a fuzzy set theory method to deal with the imprecision of language and the ambiguity of human judgment. His research lacks necessary experimental data [10]. Yun believes that, with the development of economic globalization, the quality competition among enterprises has been extended to the supply chain. In order to achieve sustainable development, enterprises must change the traditional closed "vertical integration" mode. He studied the multiattribute decision-making problem and used binary linguistic information to estimate the performance of green supply chain in the low-carbon agricultural economic environment. Then, he proposed the 2-tuple power Einstein weighted geometric operator to summarize the 2-tuple linguistic information and then used the 2tpewg operator to evaluate the performance of the green supply chain in the low-carbon agricultural economic environment by using the 2-tuple linguistic information. His research is not accurate enough [11]. Miret studied the multiobjective optimization problem from the perspectives of economy, environment, and society. He quantified the environmental dimension through the life cycle assessment, especially the ecological cost method. For the latter, he proposed a new method based on financial accounting analysis to estimate direct, indirect, and induced job creation. Once the superstructure is described, the optimization problem is described as a mixed integer linear programming, which considers the seasonality of biomass, geographical availability, biomass degradation, process conversion technology, and final product requirements. Although his method for solving multiobjective optimization problems has a certain optimization effect, it lacks specific steps [12].

With the establishment of a central database between distributed computer units, an information sharing environment within the organization has emerged. Now, every unit of the organization can get all kinds of information needed from the database at any time and process it in its own unit. Simultaneously, the transaction processing system within the organization and the customer support system outside the organization are gradually connected, and a unified EDI standard compatible with various industries has been established, thus forming a supply chain process management system [13]. Each actor becomes the knowledge node in the internal supply chain of the organization, and the competitiveness of each technical link in the organization depends on the innovation power of these knowledge nodes [14]. These knowledge nodes are connected together to form a powerful internal supply chain system of the organization. The more competitive each knowledge node in the organization is, the more capable the organization will be to expand its internal supply chain, which in turn promotes the expansion of the enterprise scale [15]. In the industrial cluster or the supply chain governance environment, the network characteristics of the organization are more obvious [16]. Any subject can ingest property rights from network relational capital and expand the boundary of its information and decision-making capabilities [17, 18]. Large enterprises embed their databases and system software on the Internet, which can enhance the functions of their system software and reduce their operating costs. Small businesses or individual actors have a greater flexibility in using network capital [19]. In most cases, the network relationship of industrial clusters or supply chain governance 
is always conducive to the externalization of enterprise production links or knowledge nodes. The emergence of virtual organizations is based on information sharing, organizational transparency, and independent information capabilities of actors. Each of the actors throughout the supply chain can flexibly extract the fruits of related industrial links with their own core advantages. In this environment, the formal form of organization becomes redundant, and the informal teamwork becomes extremely competitive [20]. This flexible organizational form liberates the individual core capabilities of the actors from the rigid formal organization and combines these core advantages with the help of network relationships and electronic connections and further integrates the entire body on a larger scale $[21,22]$. The core competitiveness of each knowledge node of the supply chain is connected, so that the competition between enterprises becomes the competition between supply chains.

The main research sequence of this paper is as follows: Section 1 is an introduction, including the research background, significance, literature review, and main innovation mentioned in this paper. Section 2 mainly introduces customer behavior, cross-border e-commerce, and green supply chain. Section 3 mainly introduces the cross-border e-commerce green supply chain action mechanism and model simulation experience, including data acquisition, data preprocessing, model establishment, and supply chain evaluation weight. Section 4 mainly discusses and analyzes the experimental results. Section 5 is the summary of the whole research.

This article deconstructs the total factor efficiency of green supply chain companies into the total factor management efficiency of green supply chain companies and the full factor environmental efficiency of green supply chain companies from the two-dimensional level of management and environment and deeply explores the root causes of inefficiency of green supply chain companies. The internal and external environments provide a reliable basis for seeking a path to improve the efficiency of all elements. Simultaneously, the relevant theories of the green supply chain are researched, to construct a green supply chain operation model and analyze the model's process design and index system construction. This paper extracts transportation cost reliability, transportation timeliness reliability, and transportation safety and reliability. It has certain reference significance for the improvement of the theory of transportation mode choice influence.

\section{Customer Behavior and Green Supply Chain}

2.1. Customer Behavior. Customer demand is the primary link of service design. The ability to accurately obtain customer needs will directly affect the quality of the entire service design and is related to the ability to design products or services that satisfy customers. The determination of customer needs is mainly done by the service designer. The information obtained in a short period of time cannot guarantee accuracy and completeness, so it will take a long time to complete. In addition, it is necessary to ensure that the accuracy of obtaining customer demand information is very important and determines the success or failure of service design. Forecast is the first part of income management, soul of income management, and important foundation of the other three parts of income management. In reality, market-related departments of most companies will predict and analyze the market demand for their products. The more accurate the market forecast, the more targeted the company's market strategies, such as pricing [23].

With the development of service enterprises and changes of business environment, customer loyalty can make enterprises occupy a favorable position in the market competition, have greater pricing space and market advantages, and have a great impact on the profitability and competitive strategies of service enterprises. Loyal customers can save the cost of developing new customers and reduce the transaction and service costs of customers. Simultaneously, it also brings higher premium income to the enterprise, which is mainly reflected in the basic profit and the profit brought by the increase of purchase quantity. Moreover, in most industries, loyal customers are less price-sensitive and have higher tolerance. They are willing to buy products and services of the enterprise at full price instead of waiting for a discount and price reduction, which makes loyal customers pay more than new customers, while enterprises sell more products at a full price and obtain a premium income [24].

2.2. Cross-Border E-Commerce. The cross-border e-commerce supply chain process is shown in Figure 1. With the increasing trade exchanges among countries in the world, the future trade will be presented in front of the world in a new way and channel of cooperation, and the development of cross-border e-commerce will appear as a new trend of a larger market, with more profits, better products, and being closer to the consumers. Under the environment of market economy, the development of an organization is not only constrained by its own resources but is also directly or indirectly influenced by the external environment. In the era of Internet and globalization, the developmental activities of organizations are increasingly closely related to the external environment. Therefore, if an organization can make full use of the external macroenvironment to "follow the trend," it will greatly promote the development of the organization; otherwise, it will bring many obstacles to the development of the organization. Therefore, it is of great significance for the development of the organization to analyze the macroenvironment faced by the organization [25].

In the Internet era, the network connects the world as a whole, and the characteristics of globalization and decentralization are increasingly obvious. In particular, the development of cross-border e-commerce is not constrained by time and space. Internet users can purchase and trade products from any country in any place at any time through the Internet with the help of cross-border e-commerce platforms, so as to realize "global trading" in a real sense and promote the flow of global capital, products, and other elements across the world [26]. 


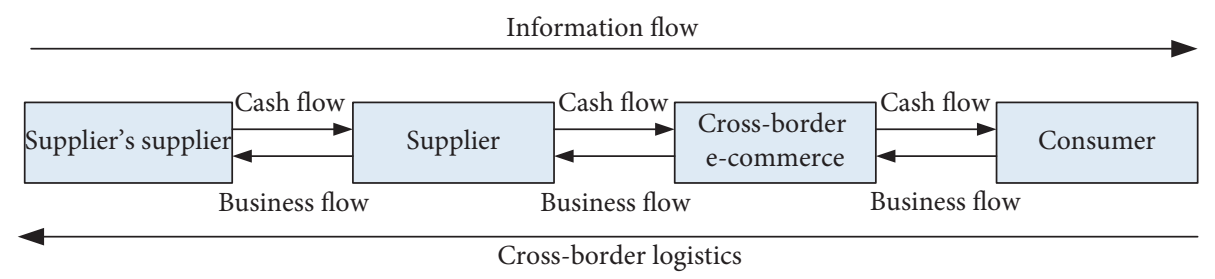

FIgURE 1: Cross-border e-commerce supply chain process.

2.3. Green Supply Chain. According to the theory of green supply chain management, the objects of green supply chain management include raw material suppliers, sellers, logistics providers, and so on. In the process of implementing green supply chain management, the green requirements of each link in the supply chain must be clear. Only when every link is "green" can we promote the development of green supply chain from inside to outside and also promote the formation of green procurement market system. To distinguish common products from green products, product green degree is born. It represents the coordination degree between green products and environment and is an evaluation index. Generally speaking, the greener a product is, the more environmentally friendly it is [27].

The output vector of the hidden layer of BP neural network is

$$
Y=f_{1}\left(\sum_{i} w_{i j} x_{i}+b_{i}\right) .
$$

The output vector of the output layer is

$$
Z=f_{2}\left(\sum_{j} w_{j 1} x_{i}+b_{1}\right) \text {. }
$$

Here, $x_{i}$ is the input layer input vector and $x_{j}$ is the hidden layer input vector.

The modified value of the connection weight from the output layer to the hidden layer is

$$
\Delta w_{i j}=-\eta \frac{\partial \varepsilon}{\partial w_{i j}} .
$$

The modified value of the connection weight from the hidden layer to the output layer is

$$
\Delta w_{j 1}=-\eta \frac{\partial \varepsilon}{\partial w_{j 1}} .
$$

Here, $\eta$ is the learning rate of the BP neural network model, and the general value range is the interval $(0,1)$.

For each factory $i$ and product $p$, the purchase of raw materials plus the production of products should equal the amount of products shipped from the factory to the warehouse plus the amount of raw materials consumed [28]:

$$
\mathrm{PU}_{j p t}+\sum_{i \in \mathrm{OUT}(P)} W_{i j p t}=\sum_{k} \mathrm{Q}_{j k p t}^{\mathrm{PL}}+\sum_{i \in \mathrm{IN}(P)} W_{i j p t} .
$$

Here, $\mathrm{PU}_{j p t}$ represents the amount of raw materials purchased by factory $j$ in the production of product $p$ at period $t$ and $W_{i j p t}$ represents the input or output of product $p$ in plant $j$ at period $t$ under equipment $i$.

The following material conversion relationship exists for equipment $i$ of plant $j$ :

$$
W_{i j p t}=\mu_{i p}+W_{i j p^{\prime} t} .
$$

Here, $\mu_{i p}$ represents the material conversion coefficient.

The original inventory plus the transportation volume from the factory to the warehouse equals the flow from the warehouse to the market plus the final inventory, which is written as follows:

$$
\mathrm{INV}_{k p t-1}+\sum_{j} Q_{j k p t}^{\mathrm{PL}}=\sum_{l} Q_{k l p t}^{\mathrm{WH}}+\mathrm{INV}_{k p t}
$$

The sales volume of products on the market depends on the quantity allocated by the warehouse, which is written as follows:

$$
\sum_{k} Q_{k l p t}^{\mathrm{WH}}=\mathrm{SA}_{l p t}
$$

The relationship between the environmental impact factors of product storage and the geographic location of the facility is not obvious, but the material flow in different regions will be different. Therefore, the emissions at this stage are only affected by the material flow as follows:

$$
\begin{aligned}
I_{p s} & =f_{p s} \sum_{g} F_{p s, g}, \\
\sum_{g} F_{p s, g} & =\sum_{k} \sum_{p} \sum_{t} \mathrm{INV}_{k, p, t}, \\
I_{p s} & =f_{p s, k} \sum_{k} \sum_{p} \sum_{t} \mathrm{INV}_{k, p, t} .
\end{aligned}
$$

As it is assumed that the technical equipment and processes of the company's branches are basically the same, the impact factors are not regionally dependent, so GHG emissions and production have a certain proportional relationship as follows:

$$
\begin{aligned}
I_{p p} & =\sum_{g} f_{p p} F_{p p, g}, \\
F_{p p, g} & =W_{i j p t} .
\end{aligned}
$$

NPV is obtained by converting the cash flows generated in each period and then adding them up as follows:

$$
\mathrm{NPV}=\sum_{t} \frac{\mathrm{CF}_{t}}{\left(1+i_{r}\right)^{t-1}}
$$

Here, $i_{r}$ represents the interest rate. 
In the coordination relationship of green supply chain of large-scale catering enterprises, the evaluation and selection of green suppliers are the primary problems to be solved. Different from the traditional supplier evaluation and selection, green supply chain management requires large-scale catering enterprises not only to consider the economic performance of the enterprise but also to pay attention to the environmental performance objectives. Due to the large number of raw materials in large-scale catering enterprises, through the different impact of raw materials on the economic and environmental performance of enterprises and the influence of large-scale catering enterprises on raw material suppliers, the procurement objectives of raw materials are determined, targeted supplier evaluation standards are establisheed, and the green practice of suppliers is influenced, so as to improve the environmental performance of the whole supply chain [29].

\section{Cross-Border E-Commerce Green Supply Chain Action Mechanism and Model Simulation Experiment}

3.1. Data Acquisition. Customer behavior analysis is based on positioning and consumption information. Therefore, this paper mainly obtains the required data from location and client databases. Simultaneously, to encourage customers to purchase using cards, to ensure the effectiveness of data collection, customers who carry membership cards can enjoy a certain discount [30].

(1) Customer information: the information in this part comes from the client's database, which mainly includes the customer's name, age, corresponding tag number, income, education level, occupation and hobbies.

(2) Record of consumption behavior: the consumption behavior records that need to be collected in this part mainly include the serial number of the entertainment facility, consumption price of each facility, area and category of the entertainment facility, and consumption amount of customers in each area.

(3) Record of customer activity scope: the record of customer activity range mainly includes the time when customers enter and exit, time that customers stay in each area of the venue, number of times customers appear in each area, and number of people included in each area in a certain period of time [31].

3.2. Data Preprocessing. Green supply chain partners choose 24 secondary indicators of the evaluation system as input vectors. The historical data under each index are collected by field investigation and brought into the neural network for training. The output vector of the network's only output layer is used as the evaluation result of suppliers. The first part is to train the established BP neural network. First, normalize the sample data, set the appropriate training parameters, and bring the sample data into the BP neural network for trial calculation until the output is less than the allowable error value. In the second part, the test data is brought into the trained BP neural network to get the output value, that is, the final output value. After the final output result is obtained, it is necessary to use the function to inverse-normalize the operation result, so as to facilitate the selection of multiple evaluation objects and select suppliers that meet the requirements through comparison.

3.3. Model Establishment. The green supply chain model is shown in Figure 2. This paper divides the operation mode of green supply chain into four stages and puts forward improvement tools for the functional modules in each stage. Each enterprise can use the tools in the module to improve the green supply chain, so as to improve the operation efficiency of the enterprise green supply chain. The initial formation of the operation mode of green supply chain is a comprehensive, modern, and circular development management mode initially formed by the influence of value holding and value driving factors, which determines the value goal of implementing green supply chain and comprehensively considers the internal and external obstacles and advantages.

The green supply chain of core enterprises in the supply chain is a supply chain mode with the manufacturer as the core to promote and pull, which fully considers the whole life cycle of products and the needs of final customers. The operation results and evaluation of the green supply chain operation mode are mainly composed of value creation and value acquisition. According to the value objectives of the mode operation and path selection and implementation of the mode operation, the composition structure of the main benefits of all parties can be determined. Simultaneously, with the support of system support and technological innovation, it is possible to provide value acquisition for stakeholders in the supply chain [32].

3.4. Supply Chain Evaluation Weight. The evaluation scale set refers to the scale for evaluating each indicator, which can be expressed in a variety of ways such as grades and scores, and varies with different evaluation needs. According to the green level evaluation requirements of the green supply chain, this article uses a graded approach to evaluate it. The construction of the judgment matrix is to compare the elements in the element set at each level and then determine the relative importance of the two elements and assign a certain value. Based on the results of the interview survey, this paper uses the arithmetic average method for operation and processing and establishes a secondary index after decomposition.

3.5. Model Checking. First, according to the two-stage method, confirmatory factor analysis was used to test the measurement model. The reliability of the questionnaire is evaluated using Cronbach's $\alpha$ coefficient and composite reliability. This article uses a two-factor analysis of variance to test the relationship between the two types of social cues and the participants' social presence. The relationship 


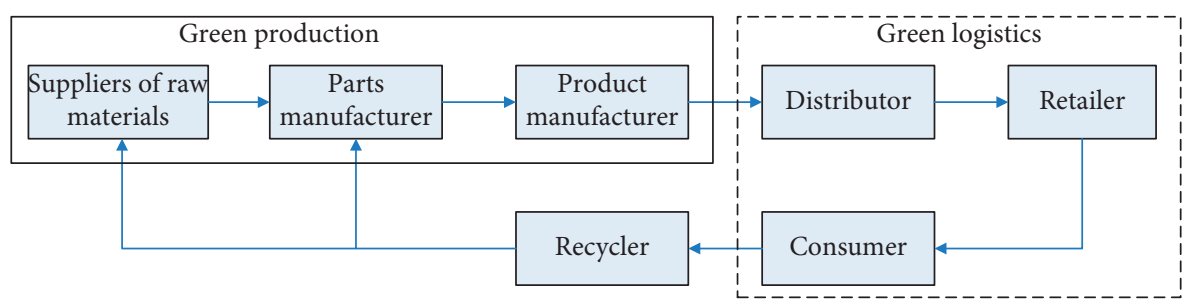

Figure 2: Green supply chain model.

between the two types of social cues and behavioral willingness was further tested through analysis of variance. After verifying the relationship between social cues and social presence, the structural equation model was further used to test the relationship between social presence and subsequent variables [33].

\section{Model Simulation Results}

4.1. Customer Behavior Analysis. The demand density faced by the two manufacturers is shown in Table 1. Assuming that the initial inventory quantity of two manufacturers is 100 , simulate the optimal price sequence and equilibrium price of the two manufacturers when the initial inventory quantity is the same. It can be seen that both manufacturers will adopt low prices at the beginning of the sales period. When the initial inventory is the same, the price conversion time of manufacturer 2 is faster than that of manufacturer 1 . This is because the calculation example assumes that the demand density faced by manufacturer 1 is higher than that of manufacturer 2 . Therefore, manufacturer 2 must "first move" to make itself in strive for more revenue in the competition [34].

Keep other parameters unchanged, when the simulated initial inventory quantity is the same. The change of conversion time under different $\alpha$ values is shown in Table 2 . It can be seen from the table that obviously as $\alpha$ increases, the time for manufacturers to use high prices decreases, and the time to use low prices increases. This is because, under the circumstance that the total demand remains unchanged, the larger the $\alpha$, the smaller the proportion of the second category of customers and the relative reduction in the demand faced by the two manufacturers during dynamic pricing, which increases the risk of surplus inventory at the end of the period, so the price must be adjusted downward in hope of increasing the probability that customers are willing to buy and reducing the possibility of surplus inventory [35].

Using the factor analysis results output by SPSS software, we can get the objective weight result of the evaluation of innovation ability of import cross-border e-commerce platform, which makes the comprehensive evaluation of each platform objective and accurate. The analysis results show that the service innovation of import cross-border e-commerce platform needs to consider both internal and external factors. The internal factors include the staff's culture and quality, platform's own network technology level, and so on, and the external factors include the change of consumer demand brought by social progress [36]. The comprehensive score of service innovation ability of each import cross-border e-commerce platform is shown in
TABle 1: Demand density faced by the two vendors.

\begin{tabular}{lllllllll}
\hline$P 1=100$ & 0.49 & 0.38 & 0.53 & 0.30 & 0.59 & 0.26 & 0.64 & 0.23 \\
\hline$P 2=120$ & 0.39 & 0.44 & 0.44 & 0.35 & 0.47 & 0.28 & 0.51 & 0.25 \\
$P 3=140$ & 0.27 & 0.48 & 0.37 & 0.40 & 0.39 & 0.32 & 0.43 & 0.29 \\
$P 4=160$ & 0.24 & 0.53 & 0.31 & 0.43 & 0.35 & 0.36 & 0.38 & 0.33 \\
\hline
\end{tabular}

TABle 2: Price conversion time under different $\alpha$ values.

\begin{tabular}{lllllllll}
\hline$\alpha=0.1$ & 112 & 623 & 795 & 961 & 94 & 583 & 767 & 914 \\
\hline$\alpha=0.2$ & 145 & 587 & 774 & 923 & 121 & 545 & 758 & 865 \\
$\alpha=0.3$ & 172 & 567 & 732 & 861 & 150 & 509 & 714 & 831 \\
$\alpha=0.4$ & 212 & 554 & 713 & 858 & 209 & 527 & 685 & 818 \\
$\alpha=0.5$ & 284 & 548 & 689 & 822 & 258 & 494 & 637 & 783 \\
$\alpha=0.6$ & 335 & 527 & 653 & 804 & 314 & 501 & 628 & 766 \\
$\alpha=0.7$ & 362 & 503 & 627 & 773 & 345 & 492 & 596 & 738 \\
$\alpha=0.8$ & 384 & 473 & 606 & 739 & 365 & 457 & 572 & 690 \\
$\alpha=0.9$ & 406 & 458 & 582 & 711 & 385 & 437 & 559 & 671 \\
\hline
\end{tabular}

Figure 3. The scores of various import cross-border e-commerce platforms in the market are quite different, which indicates that there is a big gap between the strengths and weaknesses of service innovation ability. Among them, the comprehensive score of platform $A$ is the highest, which is 3.67; the score of platform $B$ and platform $C$ is not much different, which is 0.79 and 0.72 , respectively; the score of platform $D$ is -0.47 , ranking the fourth; the score of platforms $E$ and $F$ is significantly different from those of the previous platforms, which are -1.46 and -2.39 , respectively. The service innovation ability needs to be strengthened [37].

The change of customer status with time and parameters is shown in Figure 4. When the utility of social preference increases, the curve of buy increases as a whole, so hesitant customers are more willing to buy goods than give up. When all the parameters are reduced, the number of customers who buy decreases significantly and the number of customers who give up buying increases significantly. When the contact between customers is closer, compared with discount, social preference utility plays a greater role, and customers trust more the recommendation of friends and the reputation of sellers. When the utility of time to customers with deposit becomes smaller, more customers are willing to wait, and the number of customers with deposit increases more rapidly and the curve is steeper [38].

4.2. Evaluation Index Analysis. The degree of collaboration between cross-border e-commerce and logistics in different regions is shown in Table 3 and Figure 5. From the table, we 


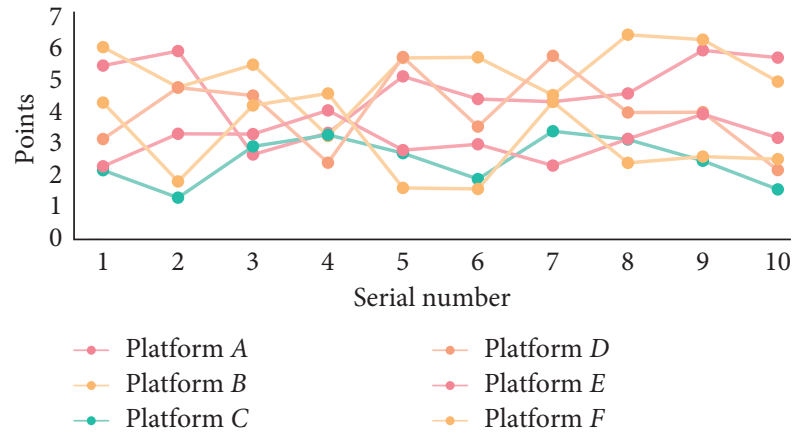

Figure 3: Comprehensive scores of service innovation capabilities of various imported cross-border e-commerce platforms.

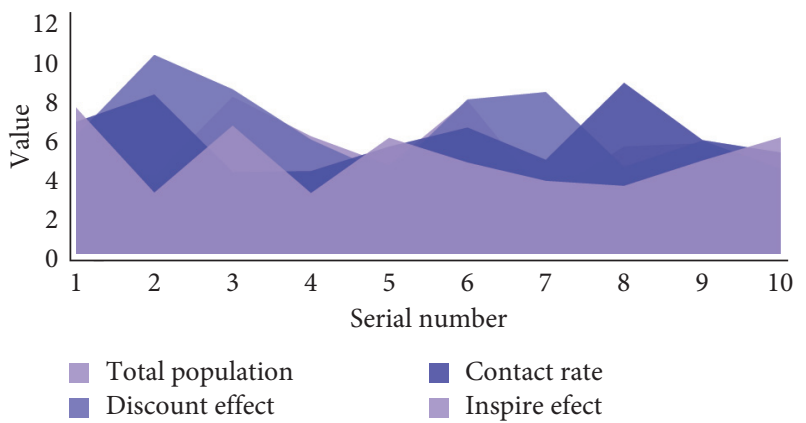

FIGURE 4: Customer status changes with time and parameters.

can see that the order degree of the east, middle, and west cross-border logistics subsystems is increasing as a whole, and the numerical difference is not big, and the fluctuation range basically remains at about $0.2 \sim 0.6$. Relatively speaking, the order of the cross-border logistics subsystem in the central region is slightly higher than that of the east and west, reaching 0.653 in 2018. In recent years, the logistics industry of China's cross-border e-commerce has developed rapidly, and the construction of related logistics infrastructure has been continuously improved, which has also laid a solid foundation for the further development of the cross-border logistics industry [39].

The optimal decisions for the green efficiency of different products are shown in Table 4 and Figure 6. In the process of collaboration between cross-border e-commerce enterprise think tanks and cross-border e-commerce information service related platform institutions, factors such as synergy benefits, synergy costs, and speculative returns affect the collaboration of cross-border e-commerce enterprise think tanks and related platforms. However, because of the different modes and contents of information services, crossborder e-commerce enterprise think tanks will be affected by other factors in the process of collaboration with different platforms. Strengthening the connection between crossborder e-commerce enterprise think tanks and cross-border e-commerce information service related platforms is of great significance for the effective integration of information resources and the transformation of resources from decentralization to aggregation [40].

The result of index weight calculation is shown in Figure 7. In the evaluation index system of $\mathrm{B} 2 \mathrm{C}$ cross-border
TABle 3: Cross-border e-commerce and logistics collaboration in different regions.

\begin{tabular}{lccc}
\hline Years & East & Central & West \\
\hline 2014 & 0.048 & 0.036 & 0.089 \\
2015 & 0.059 & 0.059 & 0.098 \\
2016 & 0.079 & 0.076 & 0.182 \\
2017 & 0.108 & 0.136 & 0.104 \\
2018 & 0.217 & 0.148 & 0.143 \\
\hline
\end{tabular}

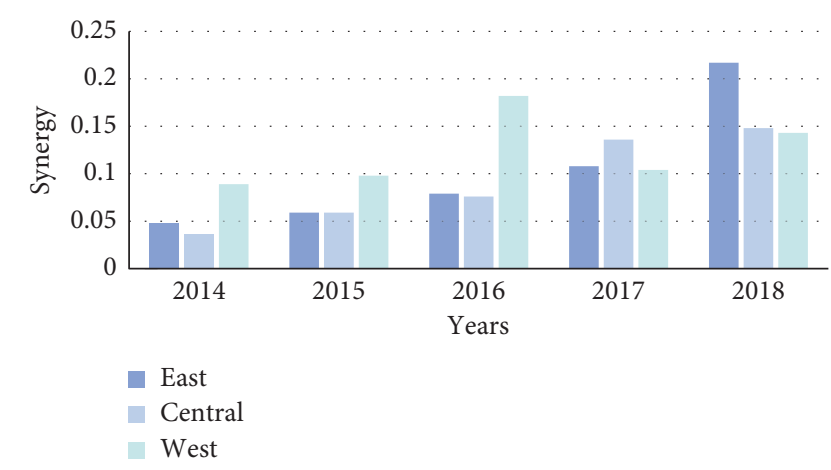

Figure 5: Cross-border e-commerce and logistics collaboration in different regions.

e-commerce overseas warehouse construction mode selection, the weights of service quality, market competition environment, platform characteristics, and supporting environment are $0.4335,0.3049,0.1615$, and 0.1001 , respectively. The market competition environment includes three specific indicators, namely, the proportion of online shopping consumers, e-commerce penetration rate, and Internet penetration rate. According to the calculation results of Yaahp software, the weights of the three are $0.0835,0.2037$, and 0.7128 respectively, and the test coefficient $\mathrm{CR}=0.0300<0.1$, passing the consistency test. The order of consideration is the Internet penetration rate, e-commerce penetration rate, and proportion of online shopping consumers. This is mainly because the Internet is the basis for the survival of cross-border e-commerce. The Internet penetration rate of the target country market has the greatest impact on people's online shopping demand, and it is also important for $\mathrm{B} 2 \mathrm{C}$ cross-border e-commerce to choose overseas warehouse.

4.3. Model Test Results. Through software analysis, the corresponding cross-border e-commerce company supply chain risk index layer and the weight value of each index corresponding to the total index are obtained, as shown in Table 5. According to the weight data table, it can be determined that the transaction risk has the greatest impact on the risk level of the cross-border e-commerce company supply chain risk, with a corresponding weight value of 0.42 ; that is, if the cross-border e-commerce company supply chain has a risk, the risk that is most likely to occur is transaction risk, which can also be understood as the probability of transaction risk occurring at $42 \%$. The second is the environmental risk, with a corresponding weight value 
TABle 4: The optimal decision of green efficiency of different products.

\begin{tabular}{lccr}
\hline \multicolumn{2}{c}{ Centralized decision } & & \multicolumn{2}{c}{ Decentralized decision-making } \\
\hline $\operatorname{Pr}$ & $\operatorname{Pd}$ & Pr1 & 57.76 \\
50.97 & 58.11 & 58.38 & 60.67 \\
54.38 & 61.53 & 62.16 & 64.15 \\
58.62 & 65.76 & 66.69 & 68.34 \\
63.93 & 71.07 & 72.13 & 73.26 \\
70.51 & 77.65 & 78.52 & 79.4 \\
79.28 & 86.42 & 86.51 & 87.55 \\
91.97 & 99.11 & 97.1 & 98.68 \\
111.64 & 118.7 & 111.5 & 113.5 \\
143.1 & 150.2 & 130.8 & \\
\hline
\end{tabular}

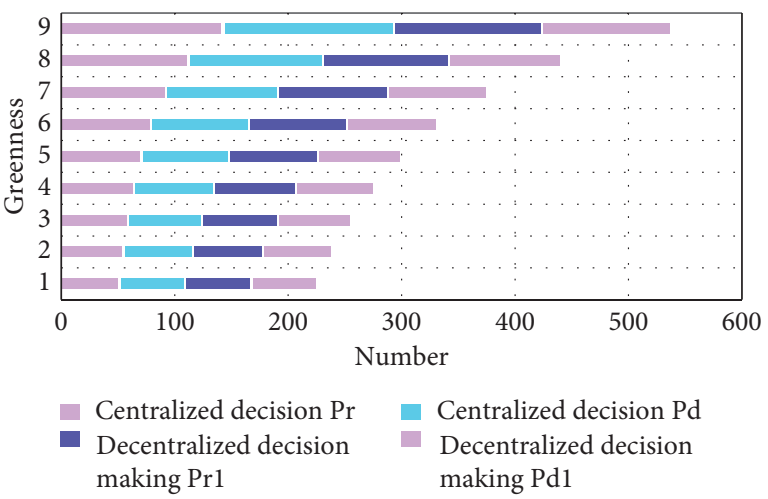

Figure 6: Optimal decisions for green efficiency of different products.

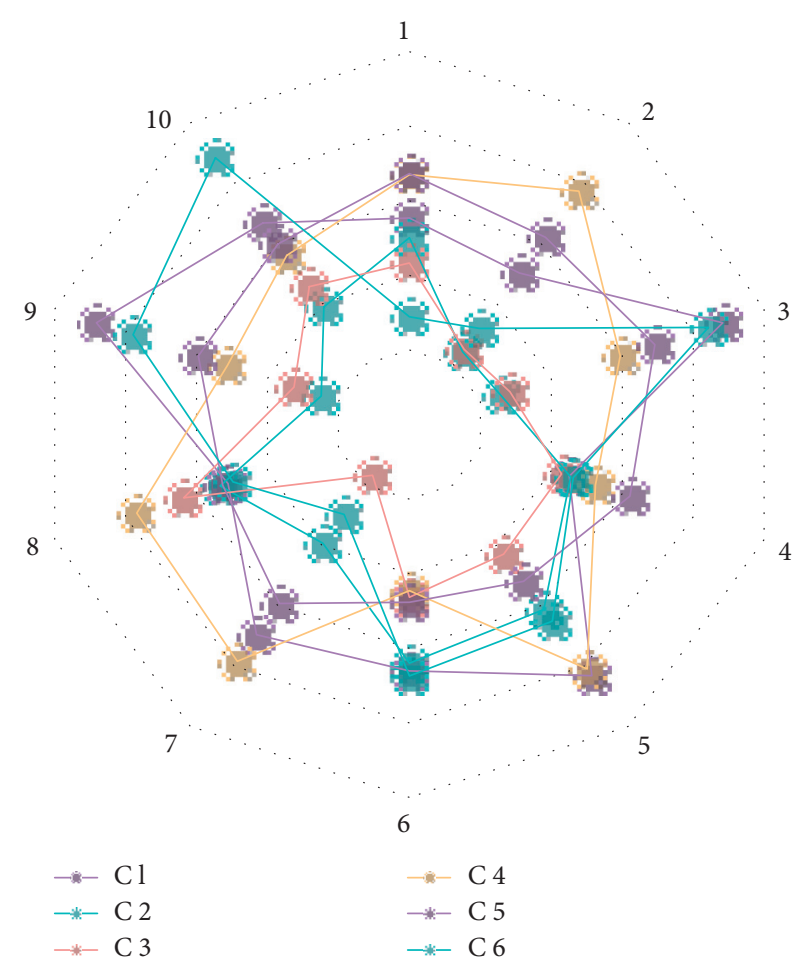

Figure 7: Result of index weight calculation.

of 0.31 , which can also be understood as the probability of environmental risk occurring at $31 \%$. The third is the crossborder logistics risk, with a corresponding weight value of
TABLE 5: Weight value of each indicator.

\begin{tabular}{lcc}
\hline First level indicator & Weights & $\begin{array}{c}\text { Comprehensive } \\
\text { weight }\end{array}$ \\
\hline Cross-border logistics risk & 0.76 & 0.17 \\
$(0.22)$ & 0.24 & 0.05 \\
\hline Transaction risk (0.42) & 0.94 & 0.39 \\
\hline \multirow{2}{*}{ Internet marketing risk (0.05) } & 0.06 & 0.03 \\
\hline & 0.80 & 0.04 \\
Environmental risk (0.31) & 0.20 & 0.01 \\
\hline & 0.45 & 0.14 \\
& 0.15 & 0.05 \\
& 0.37 & 0.11 \\
& 0.03 & 0.003 \\
\hline
\end{tabular}

0.22 , which can also be understood as the probability of cross-border logistics risk occurring at $22 \%$. The fourth is the network marketing risk, with a corresponding weight value of 0.05 ; that is, the probability of network marketing risk occurrence is relatively low, less than 0.1 . The risks of online marketing can be ignored in this article. From the overall perspective of cross-border e-commerce company supply chain risks, the most obvious impact is credit risk, with an overall weight value of 0.39 . The second is the logistics itself risk, with an overall weight value of 0.17 . The third is legal and regulatory risk, with an overall weight value of 0.14 . The fourth is the industry environmental risk, with an overall weight value of 0.11 .

The effect of information sharing cost coefficient on profit is shown in Figure 8. When the cost coefficient of information sharing between the two sides continues to decline over time, the products of cross-border export enterprises can create greater market demand and sell on the platform e-commerce platform at a higher price. The degree of information sharing in the supply chain will also be improved, and the overall supply chain will enter a virtuous cycle. If the cost coefficient of information sharing in the supply chain gradually decreases, the profits of platform providers and cross-border export enterprises and the total profits of the supply chain will be improved, and the competitiveness of the supply chain will be enhanced. In this process, the profits of the platform providers will increase faster than those of the cross-border export enterprises, and the platform enterprises will get more benefits by reducing the information sharing degree in the supply chain. 


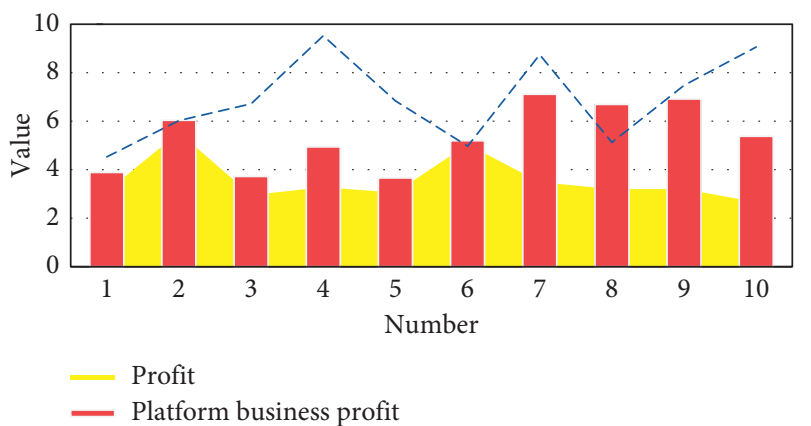

Figure 8: The impact of information sharing cost coefficient on profit.

TABLE 6: GSETFE value of green supply chain companies.

\begin{tabular}{lcccccc}
\hline Enterprise & 2014 & 2015 & 2016 & 2017 & 2018 & Average value \\
\hline Weichai Power & 0.788 & 0.842 & 0.709 & 0.761 & 0.818 & 0.936 \\
Goldwind Technology & 0.787 & 0.864 & 0.935 & 0.896 & 0.352 & 0.695 \\
Snowman shares & 0.835 & 0.638 & 0.786 & 0.707 & 0.889 & 0.884 \\
Sany heavy industry & 0.817 & 0.748 & 0.637 & 0.716 & 0.773 & 0.760 \\
TBEA & 0.850 & 0.781 & 0.693 & 0.396 & 0.472 & 0.869 \\
Zhenhua heavy industry & 0.604 & 0.553 & 0.423 & 0.767 & 0.793 \\
Haier Zhijia & 0.971 & 0.774 & 0.787 & 0.733 & 0.834 \\
Sichuan Changhong & 0.704 & 0.595 & 0.653 & 0.733 & 0.825 & 0.696 \\
Average value & 0.836 & 0.779 & 0.762 & & 0.787 \\
\hline
\end{tabular}

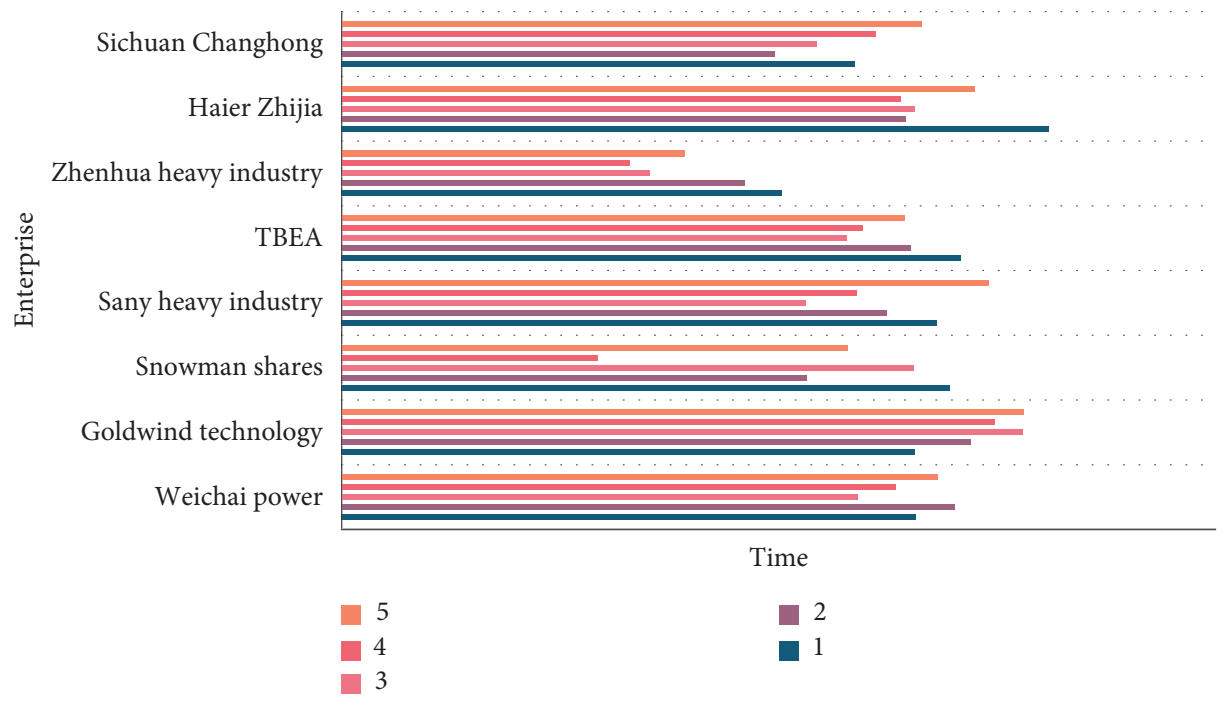

FIGURE 9: GSETFE value of green supply chain companies.

GSETFE values of green supply chain enterprises are shown in Table 6 and Figure 9. From the sample average level, without considering the influence of external environmental factors, the total factor efficiency of green supply chain enterprises in China is between 0.73 and 0.85 , and there is still $15 \%-27 \%$ room for improvement, which shows that the development potential of green supply chain enterprises in China is huge.

\section{Conclusions}

The supply chain management of cross-border e-commerce should take the ultimate goal of improving the sensitivity of the supply chain system, enhancing the competitive advantage of the enterprise supply chain, and reducing the operating cost of the enterprise supply chain and consider the construction factors, such as reasonable logistics grid and customer value. Major cross-border e-commerce companies rely on the professionalism of third-party logistics resources. The layout of cross-border logistics networks should be based on their own product characteristics and service requirements and use logistics service outsourcing resources, especially for the delivery services of the destination country of commodity delivery. It is difficult to penetrate overseas countries, and logistics outsourcing can improve the efficiency of distribution and reduce the cost at the same time. 
Now, large enterprises are facing more brutal competition. In order to highlight their main business and develop their core competitiveness, many large enterprises are also forced to get rid of some of the branches and industrial links that they are not good at and cannot afford to lose. In some new industrial areas or industrial cluster areas, this situation becomes particularly clear. Therefore, if a region wants to obtain a sustainable competitive advantage, it must adopt two strategies at the same time. One is to optimize the geographical environment and give play to the advantages of industrial clusters; the other is to participate in or create a network alliance of global supply chains, reduce logistics costs, and share.

This paper uses evolutionary game theory and mathematical modeling analysis tools to construct an evolutionary game model of core enterprises and their upstream SMEs in the supply chain based on core enterprise guarantee strategies and uses numerical simulation analysis to prove that core enterprises take guaranteed actions to promote green supply in my country The implementation of chain finance strategy is of great significance. Through the research of profit and profit distribution in the green supply chain, it provides guidance for the green supply chain to effectively select the supply chain members to cooperate and calculate and distribute the profit reasonably, so that the green supply chain management can be widely used in reality.

The construction of reasonable power mechanism, sharing mechanism, negotiation mechanism, and trust mechanism can ensure the efficient and steady operation of the green supply chain, improve the overall competitiveness of the supply chain, and achieve the win-win goal of the whole and part. Through the construction of mechanism and model, it can be concluded that when enterprises implement green supply chain operation and if node enterprises can share knowledge, negotiate, and trust with each other, then the overall revenue of the supply chain will be greatly improved, and the overall competitiveness of the supply chain will be enhanced. Due to the authors' limited knowledge level and time, it is difficult to form a systematic and complete theoretical system in a short time. There are still many limitations in this paper. For example, the analysis of the impact of customer behavior on the operation of green supply chain is not deep enough, and the combination of behavior theory and enterprise supply chain management will be the direction of further research.

\section{Data Availability}

No data were used to support this study.

\section{Conflicts of Interest}

The authors declare that they have no conflicts of interest.

\section{Acknowledgments}

This work was supported by Nanchang Institute of Technology Introduced Personnel Research Start-Up Project
Research on the Whole Industry Chain Agglomeration of Cross-Border E-Commerce (NGRCZX-20-11) and 2020 Scientific Research Fund Project of Education Department of Liaoning Province (QW202001)

\section{References}

[1] C.-H. Wu and S.-B. Tsai, "Using DEMATEL-based ANP model to measure the successful factors of E-commerce," Journal of Global Information Management, vol. 26, no. 1, pp. 120-135, 2018.

[2] K. Choudhary and K. S. Sangwan, "Benchmarking Indian ceramic enterprises based on green supply chain management pressures, practices and performance," Benchmarking: An International Journal, vol. 25, no. 9, pp. 3628-3653, 2018.

[3] Y.-C. Huang, C.-H. Huang, and M.-L. Yang, "Drivers of green supply chain initiatives and performance," International Journal of Physical Distribution \& Logistics Management, vol. 47, no. 9, pp. 796-819, 2017.

[4] Y. S. Fabio, G. C. D. Oliveira Neto, F. C. Silva, and E. C. Pompone, "Corporate profile, performance and green supply chain management: a research agenda," Ram Revista De Administração Mackenzie, vol. 18, no. 3, pp. 117-146, 2017.

[5] S. Luthra, D. Garg, and A. Haleem, "The impacts of critical success factors for implementing green supply chain management towards sustainability: an empirical investigation of Indian automobile industry," Journal of Cleaner Production, vol. 121, no. 5, pp. 142-158, 2016.

[6] C. Mahesh, B. Neha, and S. Rajesh kumar, "ANP-MOORAbased approach for the analysis of selected issues of green supply chain management," Benchmarking, vol. 25, no. 2, pp. 642-659, 2018.

[7] K. Kang, Y. Zhao, Y. Ma, and Z. Li, "Green supply chain poverty alleviation through microfinance game model and cooperative analysis," Journal of Cleaner Production, vol. 226, no. 7, pp. 1022-1041, 2019.

[8] A. Rezaee, F. Dehghanian, B. Fahimnia, and B. Beamon, "Green supply chain network design with stochastic demand and carbon price," Annals of Operations Research, vol. 250, no. 2, pp. 463-485, 2017.

[9] A. Wu and T. Li, "Gaining sustainable development by green supply chain innovation: perspectives of specific investments and stakeholder engagement," Business Strategy and the Environment, vol. 29, no. 3, pp. 962-975, 2020.

[10] E. Pourjavad and A. Shahin, "The application of mamdani fuzzy inference system in evaluating green supply chain management performance," International Journal of Fuzzy Systems, vol. 20, no. 3, pp. 901-912, 2018.

[11] T. Yun, "Model for evaluating the green supply chain performance under low-carbon agricultural economy environment with 2-tuple linguistic information," Journal of Intelligent and Fuzzy Systems, vol. 32, no. 3, pp. 2717-2723, 2017.

[12] C. Miret, P. Chazara, L. Montastruc, S. Negny, and S. Domenech, "Design of bioethanol green supply chain: comparison between first and second generation biomass concerning economic, environmental and social criteria," Computers and Chemical Engineering, vol. 85, no. 2, pp. 16$35,2016$.

[13] H.-K. Liu, D. Chen, H. Jin et al., "A survey of non-volatile main memory technologies: state-of-the-arts, practices, and future directions," Journal of Computer Science and Technology, vol. 36, no. 1, pp. 4-32, 2021. 
[14] S. Nathaniel and S. Abdul, "The nexus between urbanization, renewable energy, trade, and ecological footprint in ASEAN countries," Journal of Cleaner Production, vol. 272, 2020.

[15] S. A. Rehman Khan, A. Sharif, H. Golpra, and A. Kumar, "A green ideology in asian emerging economies: from environmental policy and sustainable development," Sustainable Development, vol. 27, no. 2, pp. 1063-1075, 2019.

[16] Z. A. Yu, B. Sark, C. Ak et al., "Is tourism really affected by logistical operations and environmental degradation? An empirical study from the perspective of Thailand," Journal of Cleaner Production, vol. 227, no. 1, pp. 158-166, 2019.

[17] S. A. R. Khan, C. Jian, Y. Zhang, H. Golpîra, A. Kumar, and A. Sharif, "Environmental, social and economic growth indicators spur logistics performance: from the perspective of south asian association for regional cooperation countries," Journal of Cleaner Production, vol. 214, pp. 1011-1023, 2019.

[18] S. A. Rehman Khan, Y. Zhang, M. Anees, H. Golpîra, A. Lahmar, and D. Qianli, "Green supply chain management, economic growth and environment: a GMM based evidence," Journal of Cleaner Production, vol. 185, pp. 588-599, 2018.

[19] S. A. R. Khan and D. Qianli, "Impact of green supply chain management practices on firms' performance: an empirical study from the perspective of Pakistan," Environmental Science and Pollution Research, vol. 24, no. 20, pp. 16829-16844, 2017.

[20] Y. Zhang and S. Khan, "Evolutionary game analysis of green agricultural product supply chain financing system: COVID19 pandemic," International Journal of Logistics, no. 4, pp. 1-21, 2021.

[21] S. Khan, K. Zkik, A. Belhadi, and S. Kamble, "Evaluating barriers and solutions for social sustainability adoption in multi-tier supply chains," International Journal of Production Research, vol. 59, no. 9, pp. 1-20, 2021.

[22] Y. Zhang and R. K. Syed Abdul, "Green supply chain network optimization under random and fuzzy environment," International Journal of Fuzzy Systems, vol. 92, no. 5, 2021.

[23] A. Longoni and R. Cagliano, "Inclusive environmental disclosure practices and firm performance," International Journal of Operations and Production Management, vol. 38, no. 9, pp. 1815-1835, 2018.

[24] V. K. Sharma, P. Chandna, and A. Bhardwaj, "Green supply chain management related performance indicators in agro industry: a review," Journal of Cleaner Production, vol. 141, no. 1, pp. 1194-1208, 2017.

[25] A. A. Teixeira, C. J. C. Jabbour, A. B. L. de Sousa Jabbour, H. Latan, and J. H. C. de Oliveira, "Green training and green supply chain management: evidence from Brazilian firms," Journal of Cleaner Production, vol. 116, no. 3, pp. 170-176, 2016.

[26] K. S. Abdallah, A. M. Fathollahi-Fard, and M. HajiaghaeiKeshteli, "A collaborative stochastic closed-loop supply chain network design for tire industry," International Journal of Engineering Research, vol. 31, no. 10, pp. 1715-1722, 2018.

[27] F. Gholian-Jouybari, M. M. Paydar, M. Hajiaghaei-Keshteli, and A. M. Fathollahi-Fard, "A Bi-objective stochastic closedloop supply chain network design problem considering downside risk," Industrial Engineeering and Management Systems, vol. 16, no. 3, pp. 342-362, 2017.

[28] A. Cheraghalipour, M. Hajiaghaei-Keshteli, and M. M. Paydar, "Tree Growth Algorithm (TGA): a novel approach for solving optimization problems," Engineering Applications of Artificial Intelligence, vol. 72, no. 6, pp. 393-414, 2018.
[29] V. Hajipour, R. Z. Farahani, and P. Fattahi, "Bi-objective vibration damping optimization for congested locationpricing problem," Computers \& Operations Research, vol. 70, no. 6, pp. 87-100, 2016.

[30] S. Rezapour, R. Z. Farahani, D. Zhang, and F. Mohammaddust, "Strategic design of a competing supply chain network for markets with deterministic demands," IMA Journal of Management Mathematics, vol. 27, no. 2, pp. 109-141, 2016.

[31] Ö. Uygun and A. Dede, "Performance evaluation of green supply chain management using integrated fuzzy multi-criteria decision making techniques," Computers \& Industrial Engineering, vol. 102, no. 12, pp. 502-511, 2016.

[32] Q. Zhang, W. Tang, and J. Zhang, "Green supply chain performance with cost learning and operational inefficiency effects," Journal of Cleaner Production, vol. 112, no. 1, pp. 3267-3284, 2016.

[33] A. Gurtu, C. Searcy, and M. Y. Jaber, "An analysis of keywords used in the literature on green supply chain management," Management Research Review, vol. 38, no. 2, pp. 166-194, 2016.

[34] J. F. Kirchoff, W. L. Tate, and D. A. Mollenkopf, “The impact of strategic organizational orientations on green supply chain management and firm performance," International Journal of Physical Distribution and Logistics Management, vol. 46, no. 3 , pp. 269-292, 2016.

[35] M.-L. Tseng, K. Tan, and A. S. F. Chiu, "Identifying the competitive determinants of firms' green supply chain capabilities under uncertainty," Clean Technologies and Environmental Policy, vol. 18, no. 5, pp. 1247-1262, 2016.

[36] M. Sawadogo and D. Anciaux, "Intermodal transportation within the green supply chain: an approach based on ELECTRE method," International Journal of Business Performance and Supply Chain Modelling, vol. 3, no. 1, pp. 43-65, 2018.

[37] K. T. Shibin, A. Gunasekaran, T. Papadopoulos, R. Dubey, M. Singh, and S. F. Wamba, "Enablers and barriers of flexible green supply chain management: a total interpretive structural modeling approach," Global Journal of Flexible Systems Management, vol. 17, no. 2, pp. 171-188, 2016.

[38] H. Younis, B. Sundarakani, and P. Vel, "The impact of implementing green supply chain management practices on corporate performance," Competitiveness Review, vol. 26, no. 3, pp. 216-245, 2016.

[39] M. A. Miranda-Ackerman, C. Azzaro-Pantel, and A. A. Aguilar-Lasserre, "A green supply chain network design framework for the processed food industry: application to the orange juice agrofood cluster," Computers and Industrial Engineering, vol. 109, no. 7, pp. 369-389, 2017.

[40] Y. Chen, W. Zheng, W. Li, and Y. Huang, "The robustness and sustainability of port logistics systems for emergency supplies from overseas," Journal of Advanced Transportation, vol. 2020, Article ID 8868533, 2020. 